\section{Liebe Freunde der BExMed,}

auch wenn der Frühling mit großen Schritten kommt, so ist die Skitourensaison noch lange nicht zu Ende.

Der Refresherkurs „Lawinenmedizin und Kälteschäden“ ist bereits Vergangenheit und der Kurs „Expeditions- und Wildnismedizin für Alpinärzte“ steht schon vor der Tür. Einen kurzen Bericht über beide Veranstaltungen gibt es in der nächsten Ausgabe.

\section{Diplomprüfungen für Alpinmedizin}

sowie Expeditions- und Wildnismedizin Die Prüfungen sind am Freitag, 09.11. 2012, 18:00 Uhr, im Rahmen der Veranstaltung „Berg \& Sport 2012 - aktueller Stellenwert der Alpin- und Sportmedizin im Gesundheitssystem“ der Österreichischen Gesellschaft für Alpin- und Höhenmedizin und der Arge Alpinmedizin (Interdisziplinäre Arbeitsgemeinschaft für Alpinmedizin an der Karl-Franzens-Universität Graz).

„Berg \& Sport 2012“ findet vom 09. bis 11. November 2012 im Veranstaltungszentrum Ramsau, www.ramsau.com, am Dachstein in der Steiermark statt. Das Programm dazu und alle Informationen sind im Internet auf der Seite www.berg undsport2012.at.
In unserem Internetangebot, www.bexmed.de, finden Sie auf der Seite Termine/ Prüfungstermine die Anmeldefristen und weitere Details zu den Prüfungen.

Während der „Berg \& Sport 2012“ wird auch unsere Jahresmitgliederversammlung 2012 stattfinden. Sobald der genaue Termin feststeht, geben wir ihn auf unserer Internetseite und in einer der nächsten Ausgaben der FTR bekannt.

\section{Weitere Termine im Frühjahr}

und im Sommer

Die alpinmedizinischen Lehrgänge im Juni „Fels- und Eiskletterlehrgang mit Schwerpunkt internistische Alpinmedizin“ sowie im Juli/September „Hochtourenlehrgang mit Schwerpunkten Bergrettung und Alpine Hubschrauberrettung“ und viele weitere Termine finden Sie wie immer unter dem Link: www.bexmed. de/termin.html.

Auf bexmed.de gibt es außerdem Informationen zu den medizinischen Aspekten bei Trekking und Expeditionen und zu unserer Gesellschaft.

Herzliche Grüße aus München Jörg Schneider

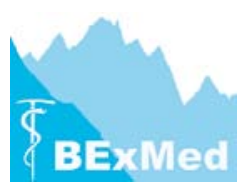

Deutsche Gesellschaft

für Berg- \& ExpeditionsMedizin e.V. c/o Kristin Krahl

Tassilostr. 2

85540 Haar

Tel.: 089/51607546

Fax: 089/51604905

info@bexmed.de; www.bexmed.de
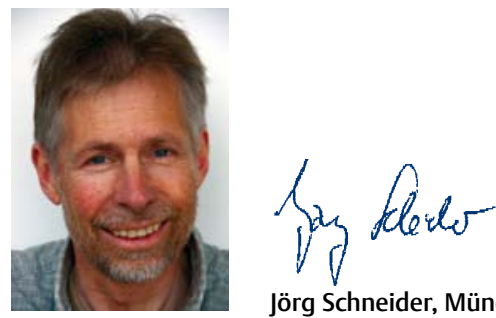

Jörg Schneider, München

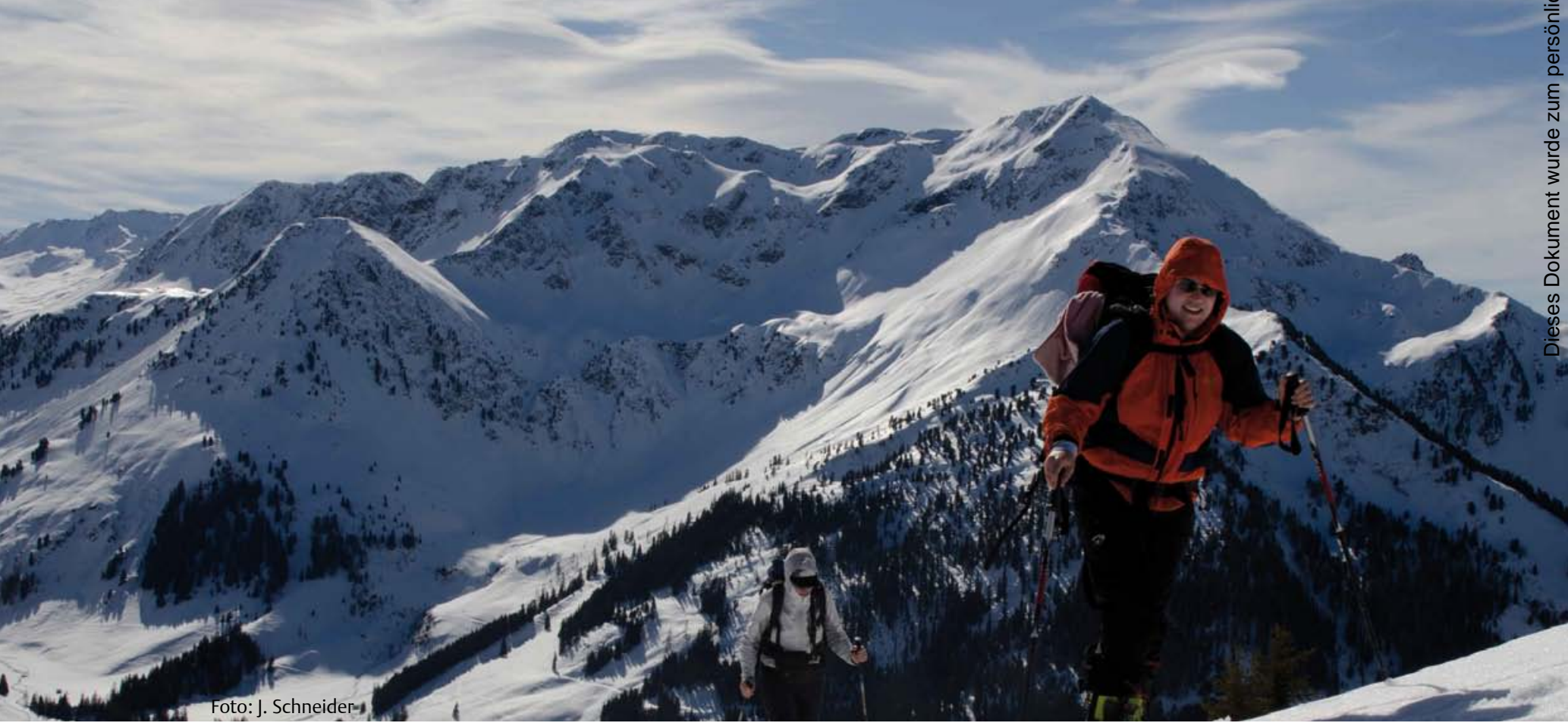

